\title{
Bolin: boletim linguístico e literário
}

Bolin: linguistic and literary journal

Josimar Gonçalves Ribeiro Moreira, Mestranda em Educação, Instituto Federal do Sudeste de Minas Gerais - Campus Rio Pomba, josimar.ribeiro@ifsudestemg.edu.br

Maria Catarina Paiva Repolês, Doutoranda em Estudos de Linguagens, Instituto Federal do Sudeste de Minas Gerais - Campus Rio Pomba, catarina.repolês@ifsudestemg.edu.br

\section{Resumo}

O artigo propõe uma estratégia pedagógica para desenvolvimento da competência escrita e interpretativa em língua materna e em língua estrangeira. Ela acontece no IFSEMG - campus Rio Pomba. A metodologia implica no uso de um jornal escolar como recurso didático para incentivar leitura literária e produções de vários gêneros.

Palavras-Chave: BOLIN, Recurso Didático, Produções de gêneros

\section{Abstract}

The article proposes a pedagogical strategy for the development of proficiency in writing and comprehension in mother tongue and foreign languages. The strategy is being used at IFSEMG - Rio Pomba campus. The methodology involves the use of a school journal as a teaching resource to encourage the reading of literature and the production of genres.

Keywords: Journal, Teaching Resource, Genre Production 


\section{V SILIDIV SIMAR}

\section{Introdução}

O Instituto Federal de Educação, Ciência e Tecnologia - Campus Rio Pomba/MG oferece cursos técnicos presenciais e à distância: Ensino Médio Integrado (Agropecuária, Alimentos, Florestas, Informática, Zootecnia); Concomitante e Subsequentes; Graduação e Pós-Graduação Lato e Stricto Sensu. A identidade principal é do eixo rural, mesmo tendo alguns cursos relacionados ao mundo urbano. Os alunos vêm de diversos lugares, tanto do campo quanto da cidade, e de classes econômicas distintas.

A maioria dos estudantes que ingressam no Instituto Federal em Rio Pomba frequentou escolas desprovidas de algum recurso como: falta de material apropriado, inacessibilidade às inovações educacionais e às diversidades culturais por residirem em locais que apresentam dificuldades de mobilidade e transporte. Isso ocasionou quase uma nulidade de leitura de qualquer gênero discursivo por parte desses discentes, transparecendo, assim, problemas de compreensão e uma deficiência quanto à utilização da correta ortografia.

Em vista disso, este trabalho, exposto inicialmente como projeto piloto, procura aprimorar a competência de leitura e escrita mediada por diferentes gêneros textuais. A meta é adicionar sugestões e adaptações ao ensinoaprendizagem da língua materna e estrangeira para melhorar o domínio com a leitura e escrita.

Busca-se, então, oferecer um jornal como recurso didático de ensinoaprendizagem apresentando um formato jovem e lúdico para assim incentivar o gosto pela leitura por meio de indicações das principais obras literárias e, com isso, motivar o adolescente através de diversos tipos de textos discursivos de diversas áreas para impulsionar a criatividade no momento da composição textual. Esse jornal, intitulado BOLIN - Boletim Linguístico e Literário tem a função de acessar e materializar textos e apresentar a língua como expressão de poder na produção cultural associando a teoria à prática.

O que justificou a busca por outra estratégia pedagógica que tentasse ser mais eficaz na condução do conhecimento será explicitada no próximo parágrafo.

$O$ insucesso discente está atrelado à dificuldade de interpretação textual, que se sustenta com uma cultura enraizada pelo desgosto de ler. A leitura não é vista pelos brasileiros como uma opção de lazer. De acordo com a pesquisa da Fecomercio RJ, 70\% dos brasileiros não leram livro algum em 2014. Este dado revela a exclusão de certos tipos de cultura pela população e transparece a falha do papel exercido pela escola, já que não consegue instigar no seu alunado o prazer de ler um livro.

Esse aspecto conflita com os propósitos da escola, já que ela seria responsável pela instrução e capacitação do indivíduo. Com isso, gradativamente, foi surgindo a constatação de que boa parte da população não dominava com eficiência as habilidades de ler e escrever necessárias para participação ativa nas 
atividades profissionais e intelectuais da nação, agravando, então, a construção do perfil do profissional que chegava ao mercado de trabalho despreparado, e acentuando a alienação para as questões ideológicas da sociedade.

Essas circunstâncias atestam a falta de domínio na leitura que causa dificuldade na interpretação textual e problemas na escrita. Isto porque há desinteresse pelas palavras carregadas de cultura contidas em qualquer suporte destinado à visualização de um texto. Com isso, onde existe pouca leitura, aparece o embaraço com a compreensão dos registros, sequenciando desconforto no momento de articular as ideias em prol de algum pensamento que mereça escrituração.

Pensar nessa inconveniência impulsionou a busca de outra estratégia pedagógica que primasse pelo ensino-aprendizagem utilizando outros recursos que pudessem propagar a língua de forma lúdica, dinâmica e usual. Logo, no próximo segmento, serão dispostos os objetivos desse projeto.

O objetivo primordial é propor uma estratégia pedagógica que desenvolva a competência escrita e interpretativa. O projeto piloto evidencia o jornal "BOLIN" como recurso didático para incentivar a leitura e produção de diversos gêneros textuais.

Neste contexto, busca-se aumentar a competência escrita e a capacidade mental e intelectual dos alunos do Ensino Médio Integrado do IFSEMG Campus Rio Pomba tendo como apoio o conceito de Letramento de Soares (2006, p.50), que subjaz "o conjunto de conhecimentos, atitudes e capacidades envolvidos no uso da língua, em práticas sociais, e necessários para uma participação ativa e competente na cultura escrita".

Depois de expor o problema, e buscar uma relação entre letramento, jornal, gêneros textuais e escrita dos estudantes, a pergunta que norteia o desenvolvimento do nosso objetivo é até que ponto a elaboração e divulgação de um jornal pode desenvolver a competência escrita e interpretativa do discente? Partindo deste questionamento, prosseguirá a fundamentação teórica que acompanhará o projeto piloto.

\section{Abordagens Teóricas}

\subsection{Gêneros Textuais}

O mundo ao nosso redor nos apresenta infinitos modelos de textos que são denominados por Luiz Antônio Marcuschi (2003) como gêneros textuais. Estes formatos são dotados de características específicas que os tipos textuais regulamentam. Segundo este autor, eles são "fenômenos históricos, profundamente vinculados à vida cultural e social" e são responsáveis pela apresentação concreta da comunicação. 


\section{V SILID IV SIMAR \\ PUC-Rio - Dias 28, 29 e 30 de julho de 2015}

Logo, para o autor, para ser considerado gênero é necessário seguir os seguintes critérios:
1. Forma estrutural (gráfico;rodapé;debate;poema)
2. Propósito comunicativo (errata; endereço)
3. Conteúdo (nota de compra; resumo de novela)
4. Meio de transmissão (telefonema; telegrama; e-mail)
5. Papéis dos interlocutores (exame oral; autorização)
6. Contexto situacional (conversação esp.; carta pessoal)

(MARCUSCHI, 2008, p.164)

A denominação de gênero está associada a uma constituição social, histórica e sua nomeação é árdua estabelecer, visto que eles se conectam, se fundem na construção de outros. Contudo, quando há imposição de identificação, o que se deve enfatizar é a função (propósito comunicativo).

Os tipos textuais são estruturas organizacionais onde os gêneros subordinam a uma natureza específica materializando-se de múltiplas formas interrelacionadas a uma função comunicativa. Essa relação é direcionada a uma "esfera da atividade humana" (Marcushi, 2008, p.155), ou seja, contexto da veiculação, à sua abrangência social, ao sistema linguístico em funcionamento e às fronteiras da escrita.

No contexto da comunicação, o intuito do homem é transmitir informações, cultura, ideologia e outras manifestações de conhecimento. Então, para a concretização das nossas práticas sociais o indivíduo cria diversas formas textuais a fim de atender à situação comunicativa propícia. Para essas criações, identificadas como gêneros, objetivam fomentar a comunicação entre as pessoas e ampliar o conhecimento acadêmico e do mundo, portanto,

(...) devem ser vistos na relação com as práticas sociais, os aspectos cognitivos, os interesses, as relações de poder, as tecnologias, as atividades discursivas e no interior da cultura. Eles mudam, fundem-se, misturam-se para manter sua identidade funcional com inovação organizacional. (MARCUSCHI, 2006, p. 25)

Sabe-se que para viver em comunidade o ser humano precisa identificar diversas formas de textos e produzi-los de maneira ativa e responsiva. A proposta aqui apresentada é de fornecer para estudo os diferentes gêneros textuais com a finalidade de reconhecê-los e posteriormente reproduzi-los como acredita Marcuschi (1996, p 15): "Quem compreende um texto sempre produz, mesmo que mentalmente, um outro texto paralelamente". 
Na seção a seguir se conhecerá com maior profundidade o gênero jornal e seu funcionamento, além de seus pontos positivos e negativos.

\subsection{Gênero Textual Jornal}

O gênero textual jornal tem como função principal veicular informação para o público. Ele se torna instrumento de comunicação e de ensino-aprendizagem quando inserido no contexto escolar. $\mathrm{E}$ isto se deve ao seu poder imensurável de influenciar os indivíduos que estão envolvidos no processo.

O motivo de escolha desse suporte consagra-se pelo oferecimento de distintas formas de representação da linguagem que são estabelecidas por uma situação dentro do modelo do discurso. Além desse fator, ressalta-se o "reconhecimento do valor da língua escrita como meio de informação e transmissão de cultura." PCN (BRASIL.1998, p. 81).

Um ponto importante a acrescentar sobre o suporte é que ele é capaz de interferir no discurso. Ele tem a especificidade comunicativa de postar os textos e torná-los acessíveis. A relação entre suporte e gênero é excêntrica, visto que ainda não foi estabelecida pelos pesquisadores qual é o nível de articulação e envolvimento que um exerce no outro.

Sua definição segundo Marcuschi (2008, p. 174) é: "[...] um lócus físico ou virtual com formato específico que serve de base ou ambiente de fixação do gênero materializado como texto." E são constituídos por três estruturas: "suporte é um lugar (físico ou virtual); tem formato específico; serve para fixar e mostrar o texto." (ibidem, p. 175).

O uso do jornal como recurso didático para o ensino-aprendizagem se vale por ofertar outro dispositivo para instrução, que vise a utilização e reflexão da linguagem. Esse objeto possibilita desenvolver "(...) habilidades de uso (textualização e compreensão de textos) e de reflexão metalinguística sobre o uso." (Bonini, 2011, p.152)

Contudo, o projeto piloto em questão se diferencia em caráter pedagógico de outros tipos de jornais escolares por conduzir toda a performance a caminho da literatura. A dinâmica sinaliza para o intenso incentivo de diversos tipos de leitura que possam culminar na criação de diferentes gêneros textuais e consequentemente viabilizar a construção autônoma do educando como autor.

Por isso, esse ambiente apontado pelo "BOLIN" procura distanciar-se da influência negativa que a mídia estende às pessoas em geral e destina-se a um modelo:

(...) equilibrado, por um lado, quanto à participação de professor(es) e alunos na sua autoria e, por outro, em termos do quanto ele refletirá o jornal convencional (algo necessário para que haja a prática de letramento midiático e jornalístico) e do quanto ele respeitará aqueles sujeitos específicos (que não são jornalistas, 


\section{V SILID IV SIMAR}

PUC-Rio - Dias 28, 29 e 30 de julho de 2015

mas alunos), possivelmente favorecendo a sua expressão como autores e, portanto, como protagonistas sociais (algo que é necessário para que o jornal exista enquanto mídia de expressão e interação dos alunos. (BONINI, 2011, p.162)

O estudo agora prosseguirá com enraizamento em direção ao ponto essencial da questão que é a utilização funcional da linguagem.

\subsection{Letramento}

Com os novos estudos, a arte de ensinar recebeu outras ampliações de significados. Houve a necessidade de distinguir os termos alfabetização e letramento que de acordo com a pesquisa de Soares (2004) define: o alfabetizado seria aquele que possui mínimas condições de codificação e decodificação dos signos, compreensão e domínio da língua materna. Já o letrado seria o indivíduo que se torna competente para realizar até mesmo tarefas complexas que envolvem a linguagem.

Esta autora ainda reforça ao relatar que: "a alfabetização é algo que deveria ser ensinado de forma sistemática, ela não deve ser diluída no processo de letramento" (SOARES, 2003, p.16). Para ela o letramento está relacionado ao "processo de apropriação de uma cultura escrita fazendo um uso real da leitura e da escrita como práticas sociais". (Ibid, 2004, p.24)

Como muitos autores, Paulo Freire também definiu a alfabetização com uma configuração parecida com a do letramento que seria:

Aprender a ler, a escrever, alfabetizar-se é, antes de mais nada, aprender a ler o mundo, compreender o seu contexto, não numa manipulação mecânica de palavras, mas numa relação dinâmica que vincula linguagem e realidade. (PAULO FREIRE, 1987, p.08)

Ao constatar a ideia que Freire tinha de alfabetização, verifica-se que a prática sociocultural da linguagem se molda consoante ao tempo, pessoas, finalidade e diversas outras facetas que a língua pode apresentar.

Para Soares (2004), o letramento está diretamente ligado às condições econômicas e sociais do indivíduo, já que estes fatores influenciam na competência escrita dos alunos. Além desses elementos, há um agravante no que tange à inacessibilidade às informações veiculadas pelas diversas formas de divulgação por grande parte da sociedade brasileira, que prejudica o desenvolvimento daqueles que se tornaram alfabetizados.

O domínio da leitura e escrita não está apoiado somente para o progresso cognitivo do cidadão, ele também é responsável pelo posicionamento do indivíduo dentro do seu contexto social, como afirma:

O uso de habilidade de leitura e escrita para o funcionamento e a participação adequados na sociedade, e para o sucesso pessoal, o letramento é considerado como um responsável por produzir 


\section{V SILIDIV SIMAR}

PUC-Rio - Dias 28, 29 e 30 de julho de 2015

resultados importantes: desenvolvimento cognitivo e econômico, mobilidade social, progresso profissional, cidadania. (SOARES, 2004, p. 74)

Sustentado pela teoria de Soares, progredirá para a próxima seção a descrição do método e a exposição das etapas desenvolvidas ao longo da aplicação do projeto piloto.

\section{Métodos}

As técnicas utilizadas para desenvolvimento do projeto piloto apresentaram características de pesquisa - ação que se define como:

(...) um tipo de pesquisa com base empírica que é concebida e realizada em estreita associação com uma ação ou com a resolução de um problema coletivo e na qual os pesquisadores e participantes representativos da situação ou do problema estão envolvidos de modo cooperativo ou participativo. (THIOLLENT, 1985, p.14)

O projeto propõe explorar, formular, construir, coletar, selecionar, analisar e elaborar plano de ação a fim de estabelecer uma interação entre a leitura e escrita dos estudantes das turmas do Ensino Médio Técnico Integrado dos $1^{\circ}$ anos do IFSEMG - Campus Rio Pomba. O mesmo se desenvolveu consoante às seguintes etapas: a) primeiramente, a fim de estabelecer contato entre alunos e textos apresentamos diversos gêneros textuais em conformidade com a temática abordada nas avaliações do ENEM e/ou de obras literárias; b) em segundo, travamos debates, julgamentos e reflexões dos assuntos propostos; c) posteriormente, partimos para a escrita de diferentes composições relacionadas com o tema discutido; d) por fim, selecionamos as melhores produções para compor o primeiro jornal. Após estas etapas, programamos e revisamos para então, imprimir e distribuir o exemplar.

Posteriormente às etapas perpassadas pelos discentes, reuniram-se dados para a análise cíclica do constructo determinado. Ao termos esses registros em mão, foi possível, de acordo com Thiollent (1985): "planejar uma melhora da prática, agir para implantar a melhora planejada, monitorar e descrever os efeitos de ação e avaliar os resultados".

O intuito da investigação é observar se a elaboração de um jornal que tem como função servir de vitrine para os melhores textos conseguiu aguçar a autoestima individual dos alunos pertencentes às turmas participantes e a incentivar a leitura e produção.

\section{Considerações}

Este artigo discorreu sobre a aplicação de uma estratégia pedagógica que articulasse a leitura, debate e análise de obras literárias a fim de incentivar o gosto 
da leitura e produção, buscar outros hábitos excluídos da vida juvenil. É de suma importância que o estudante matriculado em nossas escolas perceba que há outras formas de lazer e que ele é responsável por seu discurso e para que este não seja alienante, é preciso atentar-se para o conhecimento de mundo expressado pelos diferentes tipos de leitura.

Letramento, assunto que permeia nosso cotidiano ainda passa despercebido por muitos e este dado já está se tornando alarmante, já que um contingente de discentes lançados ao mercado vão sendo deixados à deriva das decisões políticas, econômicas e sociais da nação. Portanto, precisa-se buscar outras formas de dinamizar o ensino-aprendizagem com características inovadoras e, conforme Soares (2004), em direção a "abrir caminhos para o indivíduo estabelecer conhecimentos do mundo em que vive."

No que tange aos gêneros, eles circundam as fronteiras da escrita, concretizam o sistema linguístico em funcionamento e se tornam pilares junto à interação pessoal sendo, segundo Marcuschi (2008) "necessários para a interlocução humana".

A proposta de utilização de um jornal como recurso didático parte do desejo de buscar outros meios para a mediação do ensino-aprendizagem da língua. Que esta possa encantar os olhos dos educandos a tal ponto que eles compreendam a importância do seu domínio ao longo da vida como afirma Bonini (2011): "pensar o papel do jornal escolar convencional como um catalisador de práticas de letramento na sociedade."

O resultado do projeto piloto serviu para demonstrar um efeito satisfatório em relação ao entusiasmo dos participantes e ao progresso na escrita. A sugestão aqui descrita, nessa fase inicial, de associar a leitura de obras literárias à elaboração de diversos gêneros sob a luz do letramento e ao final do percurso agraciar as melhores produções no jornal correspondeu de forma surpreendente ao objetivo tido como alvo.

\section{Referências Bibliográficas}

BONINI, Aldair. Jornal escolar: gênero e letramento midiático no ensinoaprendizagem de linguagem. RBLA. Belo Horizonte.v.11, n.1, p. 149-175,2011. Disponível em: www.scielo.br/pdf/rbla/v11n1/v11n1a09.pdf.

BRASIL. Secretaria de Educação Fundamental. Parâmetros curriculares nacionais: língua portuguesa. Secretaria de Educação Fundamental. Brasília. 1998. $144 p$. 


\section{SILID IV SIMAR}

FREIRE, Paulo. A importância do ato de ler: em três artigos que se completam. 20a ed, São Paulo: Cortez, 1987.

MARCUSCHI, Luiz Antônio. Gêneros textuais: definição e funcionalidade. In: DIONÍSIO, Ângela Paiva; BEZERRA, Maria Auxiliadora; MACHADO, Anna Rachel (Orgs.) Gêneros textuais \& ensino. $2^{a}$ ed. Rio de Janeiro: Lucerna, 2003, p. 1936

A questão do suporte dos gêneros. MEURER, José Luiz; MOTTA-ROTH, Désirée (Orgs.) DLCV: Língua, Lingüística e literatura. João Pessoa: Idéia, 2003b. $9-40$

Gêneros textuais: configuração, dinamicidade e circulação. In: KARWOSKI, Acir Mário; GAYDECZKA, Beatriz \& BRITO Karim Siebeneicher (Orgs.) Gêneros textuais: reflexões e ensino. 2a ed. Rio de Janeiro: Lucerna, 2006. 23-36

Exercícios de compreensão ou copiação nos manuais de ensino de língua?

Em aberto, Brasília, v. 16, n.69, 1996. Disponível em: http://www.inep.gov.br/download/cibec/1996/periodicos/em_aberto_69.doc

Produção textual, análise de gêneros e compreensão. São Paulo: Parábola Editorial, 2008.

SOARES, Magda. Alfabetização e letramento: caderno do professor/Magda Becker Soares; Antônio Gomes Batista. Belo Horizonte:Ceale/FaE/UFMG,2005. 64 p.

Alfabetização e letramento. 2a Ed. São Paulo: Contexto. 2004.

Letramento: um tema em três gêneros. $2^{\mathrm{a}}$ Ed. Belo Horizonte: Autêntica. 2004.

As muitas facetas da alfabetização. In: Alfabetização e letramento. São Paulo: Contexto, 2003.

TELES. Lília. 70\% dos brasileiros não leram em 2014, diz pesquisa da Fecomercio RJ. Jornal da Globo, Rio de Janeiro. 31 de mar. de 2015. Disponível em: http://g1.globo.com/jornal-da-globo/noticia/2015/04/70-dos-brasileiros-nao-leramem-2014-diz-pesquisa-da-fecomercio-rj.html

THIOLLENT, Michel. Metodologia da Pesquisa-Ação. São Paulo: Cortez, 1985. 